\section{CAPACIDADE DOS RESERVATÓRIOS GĀSTRI. COS DE BOVINOS AZEBUADOS. I. CAPACI- DADE DO RUME EM BOVINOS AZEBUADOS MACHOS ADULTOS (ACIMA DOS 49,9 MESES)}

\author{
ORLANDO MARQUES DE PAIVA \\ Professor Catedrático \\ ANTONIO FERNANDES FILHO \\ Professor Livre-Docente \\ ANTONIO ALBERTO D'ERRICO \\ Professor Livre-Docente \\ HARUO HIGASHI \\ Técnico de Laboratório \\ Faculdade de Medicina Veterinária \\ e Zootecnia da USP
}

PAIVA, O.M.; FERNANDES FILHO, A.; D'ERRICO, A.A. HIGASHI, $H$. Capacidade dos reservatórios gástricos de bovinos azebuados. I. Capacidade do rume em bovinos azebuados machos adultos (acima dos 49,9 meses). Rev.Fac.Med.vet.Zootec. Univ.S. Paulo, 16(1/2): 33-35, 1979.

RESUMO: Determinou-se a capacidade do rume em 20 bovinos ane lorados, machos, adultos (acima dos 49,9 meses de idade), encontrando-se como média 97,13 t 2,301. Os coeficientes de correlação entre capacidade do rume e comprimento da carcaça e entre capacidade do rume e peso da carcaça mostram-se estatisticamente significantes.

UNITERMOS: A natomia, bovinos*; Rúmen*.

\section{INTRODUÇĀO E LITERATURA}

O estudo do tracto digestivo de bovinos azebuados, de há muito vem motivando, entre nós, o interesse de alguns pesquisadores, conforme documentam os trabalhos de PAIVA e ASSIS RIBEIRO $^{14}$ (1948) sobre a distância do torus pyloricus à papilla duodeni hepatica e de PAIVA e D'ERRICO15 (1949), a propósito da distância da papilla duodeni hepatica à papilla duodeni pancreatica. No primeiro deles alvitra-se que o valor médio encontrado, significantemente inferior ao definido por outros AA. para bovınos de origem européia, talvez se relacione com o menor comprimento do intestino. No segundo, ante resultados da mesma ordem, reitera-se a hipótese, em parcial oposição a achados de BLACK, SEMPLE e LUSH $^{1}$ (1934), pois, estes, confrontando mestiços de Zebu (meio sangue Zebu-Hereford e Zebu-Shorthorn) e animais puro-sangue Hereford e Shorthorn, embora afirmem que "No statistically significant differences were found . . in intestine lenght . ", reconhecem: "As noteworthy physiological and anatomical differences, the Brahman crossbred had, on average, smaller heads, larger hides, and smaller heads, larger hides, and smaller digestive tracts".

Anos mais tarde. PAIVA e BORELLI 16 retomam o tema e divulgam, mediante comunicação (1962) e publicação (1977), dados atinentes à tomada de medidas do tracto entérico, utilizando-se, para tanto, do material retirado de 40 zebuínos adultos ( 20 machos e 20 fêmeas). Impossibilitados de cotejar os números obtidos com os proporcionados pelos tratadistas, determinados, provavelmente, em taurinos, restringem-se a comentar que as médias correspondentes ao comprimento total do intestino e seus segmentos delgado e grosso, ou bem estão abaixo, ou mal superam os limites mínimos, respectivos, inscritos nos compêndios de Anatomia Veterinária.

$\mathrm{Na}$ contribuição de PAIVA, BORELLI, e PEDUTI NETO ${ }^{17}$ (1975) volta-se a examinar as distâncias que separam torus pyloricus da papilla duodeni hepatica e esta da papilla duodeni pancreatica, em bovinos de origem européia ( 21 machos e 36 fêmeas) e indiana ( 30 machos e 30 fêmeas). A análise estatística procedida, concluem os AA., nâo revela diferenças significantes entre sexos, mas evidencia-as para os restantes valores cotejados.

Ainda uma vez, PAIVA, BORELLI e PEDUTI NETO ${ }^{19}$ (1977) ocupam-se do assunto, investigando, agora, o comprimento médio do tubo intestinal e o de suas diversas secções em bovinos adultos, de raças européias ( 20 machos e 20 fêmeas), com o projetado fito de verificar se as medições anotadas divergiriam das referidas por PAIVA e BORELLI16-18. A comparação leva-os a admitir que, excluída a interferência dos sexos, a porção delgada revela diferença estatisticamente significante e somente ela é responsável pela menor extensão global daquele tubo.

Impedidos de averiguar a capacidade dos estômagos de azebuados e não azebuados, por motivos de ordem econômica, BLACK. SEMPLE e LUSH ${ }^{1}$ pesaram-nos, conjuntamente, com e sem esvaziamento do conteúdo. As desigualdades observadas, no dizer dos AA. ao que parece, influenciam os hábitos de alimentação do gado, fato assim registrado: "...The Brahmans had a distinct tendency to eat many times during the day but not a large quantity at any one time. The smaller capacity of their digestive tracts offers a plausible explanation for this peculiarity".

A despeito de sua reduzida valia, a ponto de tornarem-se quase inservíveis para efetiva equiparação, à falta de informações relativas a raça, idade, sexo, número básico de animais, estes possivelmente de origem européia, vale dizer, pelas mesmas razões invocadas por PAIVA e ASSIS RIBEIRO ${ }^{14}$, PAIVA e D'ERRICO 15 , PAIVA e BORELLI ${ }^{18}$, PAIVA, BORELLI e PEDUTI NETO17-19 (1975, 1977), resumimos adiante os elementos inseridos em diversos dos Tratados de Anatomia Veterinária: 
FAVILLI ${ }^{5}$

MARTIN E SCHAUDER 10
1931

1935

1943

1951

1960

1962

1963

1963

1963

1965
$200 l$

$102-148 I$

$100-150 l$

$180-225 l$

$102-148 l$

$200 l$

$200 l$

$200 l$

$160 l$

$140-210 l$
Da exposição preliminar apresentada extrai-se a justificativa da nova proposta de pesquisa surgida, concernente à capacidade do rume de zebuínos, de inteiro acordo com a trilha até aqui percorrida.

\section{MATERIAL E MÉTODO}

Os resultados atingidos apoiam-se nas mediçōes realizadas em espécimes anelorados, 20 machos, adultos, ou seja, já portadores dos "cantos" (caninos insiciformes) definitivos, o que nos autoriza a atribuir-lhes, no mínimo, 49,9 meses de idade (tabela de CHIEFI, PAIVA e VEIGA $\left.{ }^{3}, 1948\right)$. À época do presente estudo, objeto de comunicação (1965), esclareça-se, não se havia reunido peças bastantes, de fêmeas, para consentir os necessários cálculos.

Tão logo os animais eram eviscerados, retiravam-se unidamente, o rume e retículo; depois, através dos óstios retículo-omásico e rúmino-reticular, levava-se a efeito cuidadosa limpeza das cavidades dos aludidos reservatórios, de imediato colocados em recipiente contendo água à temperatura de $38,5^{\circ}$ centígrados, de maneira a que o rume se enchesse até igualamento das pressōes interna e externa. Procedia-se, então, ao fechamento do orifício de comunicação dos dois proventrículos e, esgotado o recipiente, media-se o líquido encerrado nesse compartimento, por meio de vasilhas previamente aferidas. De todos os exemplares colhemos apontamentos sobre procedência, comprimento (tomado da juntura entre a $7^{\mathrm{a}}$ vértebra cervical e a $1^{\text {a }}$ torácica ao promontório) e peso das carcaças. Aplicou-se às observaçōes tratamento estatístico.

\section{RESULTADOS}

$\mathrm{Na}$ relação abaixo acham-se condensadas as anotações pertinentes a cada um dos 20 casos; a elas seguem-se os correspondentes valores da média e respectivo erro padrão e do coeficiente de variação. Acompanham-nos os coeficientes de correlação entre capacidade do rume e comprimento da carcaça e entre capacidade do rume e peso da carcaça.

$\begin{array}{rlccr}\begin{array}{c}\text { Obs. } \\ \text { No. }\end{array} & \text { Procedência } & \begin{array}{c}\text { Comprimento da } \\ \text { carcaça } \\ \text { (em cm) }\end{array} & \begin{array}{c}\text { Peso da } \\ \text { carcaça } \\ \text { (em Kg) }\end{array} & \begin{array}{r}\text { Capacidade } \\ \text { do rume } \\ \text { (em } l \text { ) }\end{array} \\ 1 & \text { Araçatuba } & 69 & 239 & 94,750 \\ 2 & \text { Valparaíso } & 75 & 299 & 105,350 \\ 3 & \text { Aguapeí } & 73 & 259 & 88,500 \\ 4 & \text { Aguapeí } & 71 & 230 & 82,550 \\ 5 & \text { Aguapeí } & 73 & 241 & 100,500 \\ 6 & \text { Aguapeí } & 71 & 232 & 92,500 \\ 7 & \text { Valparaíso } & 73 & 260 & 88,350 \\ 8 & \text { Valparaíso } & 76 & 286 & 111,500 \\ 9 & \text { Posto Epitácio } & 77 & 296 & 123,500 \\ 10 & \text { Posto Epitácio } & 75 & 278 & 110,000 \\ 11 & \text { Posto Epitácio } & 79 & 242 & 109,500 \\ 12 & \text { Posto Epitácio } & 70 & 228 & 94,750 \\ 13 & \text { Araçatuba } & 70 & 259 & 86,750 \\ 14 & \text { Araçatuba } & 69 & 225 & 95,500 \\ 15 & \text { Sta. Fé do Sul } & 76 & 293 & 96,500 \\ 16 & \text { Sta. Fé do Sul } & 74 & 239 & 94,250 \\ 17 & \text { Sta. Fé do Sul } & 69 & 208 & 92,650 \\ 18 & \text { Sta. Fé do Sul } & 72 & 260 & 94,750 \\ 19 & \text { Sta. Fé do Sul } & 71 & 260 & 84,500 \\ 20 & \text { Sta. Fé do Sul } & 74 & 288 & 96,000\end{array}$

Rev. Fac. Med. vet. Zootec. Univ. S. Paulo, 16(1-2):33-35, 1979. $\overline{\bar{x}}=97,13 \pm 2,30 \quad$ C.V. $=10,57 \%$

capacidade do rume $\mathrm{x}$ comprimento da carcaça $=0,71$ significante capacidade do rume $x$ peso da carcaça: $r=0,50$ significante

\section{COMENTÁRIOS}

A rigor, vários dos trabalhos realizados na Disciplina de Anatomia Descritiva e Topográfica por PAIVA e ASSIS RIBEIRO14, PAIVA e D'ERRICO ${ }^{15}$, PAIVA e BORELLI ${ }^{16}$ e PAIVA, BORELLI e PEDUTI NETO17 $(1975,1977)$, afora os resultados a que conduziram em si mesmos, vieram subsidiar e fortalecer a suposição de BLACK, SEMPLE e LUSH ${ }^{1}$, consoante a qual os mestiços de Zebu exibiriam, comparativamente a bovinos de origem européia, tractos digestivos menores, a ponto de condicionar seus hábitos de alimentação. Embora as conclusões estabelecidas por PAIVA e ASSIS RIBEIRO ${ }^{14}$, PAIVA e D'ERRICO ${ }^{15}$ e PAIVA e BORELLI ${ }^{16}$ se inclinam a favor dessa suposição, foi a partir das publicaçōes de PAIVA, BORELLI e PEDUTI NETO 17 que ela, efetivamente, ganhou verdadeiro arrimo e passou a assumir contornos de autenticidade. Assim, se em uma (1975) as distâncias entre torus pyloricus e papilla duodeni hepatica e entre esta e a papilla duodeni pancreatica são reveladas significantemente menores, nos bovinos de origem indiana, na outra (1977), com igual recurso técnico, confere-se à porção delgada do intestino intervenção no demonstrado menos comprimento global do tubo digestivo desses animais, a ponderar-se, afirmam, as medições antes notificadas por PAIVA e BORELLI ${ }^{16}$.

Conquanto não conte, por ora, com material suficiente para verificação de dessemelhanças entre machos e fêmeas, a capacidade média do rume dos primeiros, reporta-o a presente contribuição, alcança $97,13 \pm 2,30 l$, valor altamente expressivo, até perante os limites mínimos difundidos pelos tratadistas compulsados, sempre superiores àquele número.

Fácil é inferir-se que este resultado, de certa forma previsível, está em harmonia com os fatos anteriormente assentados, relativamente a segmentos do intestino e junta-se a eles no apoio à presunção lançada por BLACK, SEMPLE e LUSH ${ }^{1}$.

Aduza-se, enfim, que os coeficientes de correlação entre capacidade do rume e comprimento da carcaça e entre capacidade do rume e peso da carcaça são estatisticamente significantes.

\section{CONCLUSŌES}

O estudo da capacidade do rume de 20 bovinos anelorados, machos, adultos (acima dos 49,9 meses de idade), permitiu fossem apuradas a média de $97,13 \pm 2,30 l$ e as seguintes medições extremas: 82,550 \& $123,500 l$.

Os coeficientes de correlação entre capacidade do rume e comprimento da carcaça e entre capacidade do rume e peso da carcaça mostram-se estatisticamente significantes.

PAIVA, O.M.; FERNANDES FILHO, A.; D'ERRICO, A.A.; HIGASHI, $H$. Capacity of the gastric compartments of the Zebu cattle. I. Capacity of the rumen of the Zebu cattle males adults (over 49,9 months). Rev.Fac.Med.vet.Zootec.Univ.S. Paulo, 16(1/2): 33-35, 1979.

SUMMARY: The capacity of the rumen (paunch) was determined in a lot of 20 Zebu cattle (Nelore breed), adult (over 49,9 months), males, by emptying this compartment of the stomach, then filling him with and under water and measuring thus contained. The authors found that the average capacity of the rumen is $97,13 \pm 2,30 l$.

UNITERMS: Anatomy, bovines*; Rumen*. 


\section{REFERÉNCIAS BIBLIOGRÁFICAS}

1- BLACK, W.H.; SEMPLE, A.T.; LUSH, A.T. Beef production and quality as influence by crossing Brahman with Hereford and Shor thorn cattle. Tech.Bull.U.S.Dep.Agric., (417), 1934.

2- $\quad$ BRUNI, A.C. \& ZIMMERL, U. Anatomia degli animali domestici. Milano, Francesco Vallardi, 1951.v.2.

3- CHIEFFI, A.; PAIVA, O.M.; VEIGA, J.S. Contribuição para o estudo da cronologia dentária do Zebu. Rev.Fac.Med.vet., São Paulo, 3: 251-69, 1948 .

4- DOBBERSTEIN, J. \& HOFFMANN, G. Lehrbuch der vergleichenden anatomie der Haustiere. Leipzig, S. Hirzel, 1963. v. 2 .

5- FAVILLI, N. Nozioni comparate di anatomia e fisiologia degli animali rurali. Torino, Unione Tipografico - Editrice Torinesse, 1931.

6- FAVILLI, N. Nozioni comparate di anatomia e fisiologia degli animali agricoli. Milano, Francesco Vallardi, 1943.

7- KATO, K. Katiku hikaku Kaibon zusitsu. [Exposição gráfica da anatomia comparada dos animais domésticos] 6.ed. Tokio, Yokendo, 1963.v.1.

8- KOCH, T. Lehrbuch der Veterinar-Anatomie. Jena Gustav Fischer, 1963. v.2.

9- LESBRE, F.X. Précis d'anatomie comparée des animaux domestiques. Paris, J.B. Baillière, 1922. v.l.

10- MARTIN, P. \& SCHAUDER, W. Lehrbuch der Anatomie der Haustiere. 3 Auf. Stuttgart, Schickhardt \& Ebner, 1935. v.3, t.2.

11- MONGIARDINO, T. Trattato di anatomia topográfica dei mammiferi domestici. Torino, Tipografia Litografica Luigi Delgrosso, 1903.
12- MONTANÉ, L. \& BOURDELLE, E. Anatomie régionale des animaux domestiques. Paris, J.B. Baillière, 1917. v.2.

13- NICKEL, R. \& SCHUMMER, A. Eingeweide. In: NICKEL, R.; SCHUMMER, A.; SEIFERLE, E. Lehrbuch der Anatomie der Haustiere. Berlin, Paul Parey, 1960. v.2.

14- PAIVA, O.M. \& ASSIS RIBEIRO, P. Distância do torus pyloricus à Papilla duodeni hepatica em bovinos mestiços de Zebu. Rev.Fac.Med.vet., São Paulo, 4: 5-26, 1949.

15- PAIVA. O.M. \& D’ERRICO, A.A. Distância da Papilla duodeni hepatica à Papilla duodeni pancreatica em bovinos mestiços de Zebu. Rev.Fac.Med.vet., São Paulo, 4:5-26, 1949 .

16- PAIVA, O.M. \& BORELLI, V. Comprimento total do intestino $\mathrm{em}$ bovinos azebuados. São Paulo, 1962. [Trabalho apresentado à XVII Conferência Anual da Sociedade Paulista de Medicina Veterinária]

17- PAIVA, O.M.; BORELLI, V.: PEDUTI NETO, J. Distância do Torus pyloricus à papilla duodeni major e desta à papilla duodeni minor em bovinos de origem européia e indiana. Rev.Fac.Med.vet.Zootec.Univ.S. Paulo, 12: 27-32, 1975.

18- PAIVA, O.M. \& BORELLI, V. Comprimento total do intestino em bovinos azebuados. Rev.Fac.Med.vet.Zootec.Univ. S. Paulo, 14(1): 171-78, 1977.

19- PAIVA, O.M.; BORELlI, V.; PEDUTI NETO, J. Comprimento total do intestino em bovinos de origem européia. Rev. Fac.Med.vet.Zootec.Univ.S. Paulo, 14(2): 189-97, 1977.

20- SCHWARZE, E. \& SCHRODER, L. Kompendium der Veterinar-Anatomie. Jena, Gustav Fischer, 1962. v.2.

21- SISSON, S. \& GROSSMANN, J.D. Anatomia de los animales domesticos. Barcelona, Salvat Editores, 1965.

Recebido para publicaçāo em: 14/08/79 Aprovado para publicação em: $31 / 03 / 80$ 